\title{
Educação inclusiva: uma escola para todos
}

\author{
Antenor de Oliveira Silva Neto* \\ Éverton Gonçalves Ávila** \\ Tamara Regina Reis Sales** \\ Simone Silveira Amorim**** \\ Andréa Karla Nunes***** \\ Vera Maria Santos******
}

\section{Resumo}

O presente trabalho trata da inserção de alunos com deficiência nas escolas de ensino regular. Assim, realizamos um resgate histórico das pessoas com deficiência e destacamos quatro fases: "fase da exclusão", "fase da segregação", "fase da integração", e "fase da inclusão total". O objetivo desta pesquisa consiste em compreender o processo histórico da educaçáo especial e da educação inclusiva para entender o movimento atual da inclusão escolar. A metodologia deste estudo ancora-se numa pesquisa bibliográfica, qualitativa e descritiva, e foi desenvolvida a partir da primeira seção da dissertação de Mestrado em Educação da Universidade Tiradentes, intitulada: "Educação Física e Capoeira como agentes de inclusão para alunos cegos: um estudo de caso". Tivemos, como base teórica, Carvalho (2007), Cunha (2015), Mantoan (2003), Stainback e Stainback (1999), Lima (2006), Sassaki (1998), Glat, Pletsch e Fontes (2007), Rodrigues (2006), entre outros. Apontaremos que a inclusão escolar plena não é uma tarefa fácil, pois é necessária uma estruturação progressiva e uma mudança significativa no sistema educacional e na concepção de inclusão por parte da sociedade em geral e, principalmente, dos profissionais escolares.

Palavras-chave: Educação Especial; Educação inclusiva; Inclusão escolar.

\footnotetext{
* Professor mestre em Educação da Faculdade de Ciências Humanas e Sociais de Paripiranga, Bahia, Brasil.

** Professor doutor da Faculdade de Administração e Negócios de Sergipe, Aracaju, Sergipe, Brasil.

*** Professora doutora em Educação pela Universidade Tiradentes, Aracaju, Sergipe, Brasil.

**** Professora doutora em Educaçáo da Universidade Tiradentes, Aracaju, Sergipe, Brasil.

***** Professora doutora em Educação da Universidade Tiradentes, Aracaju, Sergipe, Brasil.

****** Professora doutora em Educação da Universidade Tiradentes, Aracaju, Sergipe, Brasil.
} 


\section{Inclusive education: a school for all}

\section{Abstract}

The present study is about inclusion of students with disabilities in the regular school. That's way, we realize a historical ransom of the people with them and we pointed four phases: "exclusion's phase", "segregation's phase", "integration's phase" and "full inclusion's phase". The research's objective consists to understand the historic process of special and inclusive education to understand the school inclusion nowadays. This support methodologic comes from the qualitative and descriptive bibliographic research. Developed from the first section of the mastership in Education of the Tiradentes University named "Physical Education and Capoeira as agent inclusion of blind students: a case study". We had theoretical basis, Carvalho (2007), Cunha (2015), Mantoan (2003), Stainback and Stainback (1999), Lima (2006), Sassaki (1998), Glat, Pletsch and Supplies (2007), Rodrigues (2006), and others. We point out that the full school inclusion is not an easy task because it is necessary a progressive frame and meaning changes in the educational system and idea about inclusion to society and professional school mainly.

Keywords: Special Education; Inclusive education; School inclusion.

\section{Introdução}

A escola contemporânea foi planejada para atender um determinado perfil de aluno, entretanto, hoje, a demanda é outra: temos estudantes bastante diversificados. Tal demanda exige da escola uma reformulação e inovação em todo o seu sistema, com estratégias de ensino que possibilitem atender a todos os indivíduos.

A educação inclusiva traz consigo uma mudança dos valores da educação tradicional, o que implica desenvolver novas políticas e reestruturação da educação. Para isso, é necessária uma transformação do sistema educacional, ainda exclusivo, direcionado para receber crianças dentro de um padrão de normalidade estabelecido historicamente.

De acordo com Nascimento (2014), é preocupante o fato de muitas escolas ainda não assegurarem uma educação de qualidade e ter uma prática que é mais excludente do que inclusiva. Grande parte das escolas não apresentam condiçôes estruturais e didático-pedagógicas satisfatórias para atender todas as crianças, além de discriminar também os marginalizados. É preciso transformá-las, e esta transformação depende de cada um, da sociedade em geral e principalmente dos professores, pois é um passo importante para que os alunos sejam recebidos em sala de aula.

Sabemos que não é uma tarefa fácil para a escola e muito menos para o professor, mas as experiências de muitos professores têm demonstrado que é possível e gratificante trabalhar em sala de aula com diversidade e, também, implementar uma educação inclusiva, enfrentar e superar desafios com a participação daqueles envolvidos com a educação, pois a inclusão é responsabilidade de todos. 
Como garantir o acesso e a permanência de todos na escola, incluindo os alunos com deficiências, e como transformar nossa escola excludente, discriminadora, numa escola inclusiva?

É preciso atentar para as possibilidades de inclusão de pessoas com deficiência e não para as dificuldades, para assim construir uma sociedade mais digna para todos, com ou sem deficiência. Nascimento (2014, p. 13) afirma que "isso só será possível quando cada cidadáo, cada um de nós, entendermos que o movimento pela inclusão não é algo que está distante; o movimento pela inclusão é algo que deve fazer parte do nosso cotidiano".

O objetivo deste trabalho é compreender o processo histórico da educação especial e da educação inclusiva para entender o movimento atual da inclusão escolar. O desenvolvimento metodológico deste estudo ancora-se numa pesquisa bibliográfica, qualitativa e descritiva.

\title{
Educação Especial e Educação Inclusiva
}

A Educação Especial nasceu quando a educação ainda era privilégio da minoria econômica. Para falar de Educação Especial e Educação Inclusiva, é necessário entender a história, o comportamento, o contexto e os moldes da sociedade em determinada época.

Falar em inclusão é sempre desafiador, pois, para muitos, ainda é um campo desconhecido, mas para compreender melhor o discurso atual da inclusão e seus aspectos, que causam por vezes angústias e também algumas polêmicas, é preciso voltar ao tempo para compreender o processo histórico da Pessoa com Deficiência, perpassar pela educação especial até chegar ao movimento da Educaçáo Inclusiva.

Assim, de acordo com Blanco (2003), nesse processo, podemos fragmentar o tratamento dado às Pessoas com Deficiência em quatro fases diferentes:

\begin{abstract}
A primeira delas corresponde ao período anterior ao século XIX, chamada de "fase da exclusáo", na qual a maioria das pessoas com deficiência e outras condiçóes excepcionais era tida como indigna da educação escolar. Nas sociedades antigas era normal o infanticídio, quando se observavam anormalidades nas crianças. Durante a Idade Média a Igreja condenou tais atos, mas por outro lado, acalentou a idéia de atribuir a causas sobrenaturais as anormalidades de que padeciam as pessoas, explicando-as como punição, em decorrência de pecados cometidos. Assim, as crianças que nasciam com alguma deficiência eram escondidas ou sacrificadas (BLANCO 2003, p. 72).
\end{abstract}

A história humana evidencia, desde a Antiguidade, a descrição de pessoas com alteraçóes anormais por motivo genético. A essas pessoas era negado o convívio social; elas eram enclausuradas em suas próprias casas ou em outro lugar para tratamento, pelos familiares ou pelas autoridades.

De acordo com Souza (2006), a pré-história é exemplo disto, pois as pessoas com problemas intelectuais eram rejeitadas pela sociedade e abandonadas pela famí- 
lia. $\mathrm{Na}$ Antiguidade acreditava-se que estas pessoas eram dominadas pelo demônio, sendo tratadas numa concepção demonológica. E na Idade Média houve o período de escuridão para a ciência, logo, o indivíduo que não fosse "normal" poderia ser entendido como demônio ou considerado um profeta em transe.

Os padrôes sociais eram determinados sob forte influência da Igreja. Aqueles que não se enquadravam eram punidos ou condenados. Nessa época, ter um filho com alguma deficiência era visto como maldição, muitas vezes ligada a algo diabólico. Os "diferentes", assim como no período da Inquisiçáo, poderiam ser executados na forca ou queimados vivos.

Segundo Souza (2006), já no Renascimento foi considerado o processo de transformação da mentalidade, no qual ficou compreendida outra concepção de anormalidade. A partir de então, com os avanços da Medicina, surgiu a noção patológica que se aproxima do conceito dos dias atuais, marcando o início de um novo tratamento:

No século XVII, os deficientes, principalmente os com deficiência mental, eram totalmente segregados, internados em orfanatos, manicômios e outros tipos de instituiçóes estatais. Esses internatos acolhiam uma diversidade de sujeitos com patologias distintas, alguns deficientes, outros doentes (AMARAL, 2001, p. 32).

Essa fase ficou conhecida como fase da exclusão, porque qualquer pessoa que náo estivesse no padrão de comportamento e de desenvolvimento instituído pela sociedade era totalmente excluída.

Para Amaral (2001), no final do século XVIII e início do século XIX, revelou-se a segunda fase, e nela surgiram instituiçóes especializadas no tratamento para Pessoas com Deficiências. Acredita-se então ter surgido nesse período a educação especial.

Ainda de acordo com Amaral (2001), houve uma divisão do exercício educacional nessa época. Nasceu, naquele momento, uma pedagogia especializada e institucionalizada, que separava indivíduos de acordo com diagnósticos em quociente intelectual. Este primeiro momento ficou conhecido como fase de segregação, tais escolas especiais cresciam e se multiplicavam por diferentes etiologias: pessoas com cegueira, surdez, com deficiência física, intelectual, etc. Estes núcleos especiais possuíam programas próprios, como técnicos e especialistas, que constituíam um sistema de educação especial diferenciado em relação ao sistema educacional geral, ou seja, dentro do sistema educacional existiam dois subsistemas que não se interligavam: educação especial e educação regular:

Na segunda metade do século XX, especialmente a partir da década de 70 , seria a terceira fase que constitui a fase da integração, quando o portador de deficiência começou a ter acesso à classe regular, desde que se adaptasse e não causasse nenhum transtorno ao contexto escolar. Embora a bandeira da integração já tivesse sido defendida a partir do final dos anos 60, nesse novo momento houve uma mudança filosófica em direção à idéia de educação in- 
tegrada, ou seja, escolas regulares aceitando crianças ou adolescentes deficientes nas classes comuns ou, pelo menos, em ambientes o menos restrito possível. Entretanto, só se consideravam adaptar-se à classe regular como esta se apresentava, portanto, sem modificação no sistema escolar (BLANCO, 2003, p. 28).

A partir da década de 1970 começaram as reivindicaçóes. Para Nascimento (2014), as Pessoas com Deficiência, até então, sendo educadas em instituiçôes especializadas, deveriam ser reinseridas na comunidade. Esta época foi marcada por importantes mudanças na educação especial, e por consequência de mobilizaçóes dos pais de crianças com Deficiência, que queriam espaços nas escolas regulares para seus filhos, resultou no direito à educação pública gratuita para todas as crianças com Deficiência.

É importante salientar que não só os pais, mas também os profissionais passaram a reivindicar e pressionar a sociedade em geral, a fim de garantir direitos essenciais e evitar discriminaçôes.

De acordo com Nascimento (2014), as conquistas decorrentes das manifestaçôes levam ao declínio da educação especial paralela à educação regular. No lugar da expressão Deficiência passou a ser utilizado o termo "Necessidades Educativas Especiais", ampliando possibilidades para integração da Pessoa com Deficiência na escola regular.

Porém, apesar desta integração ter sido considerada um grande avanço para igualdade de direitos, houve poucos benefícios para promover de fato o seu desenvolvimento. A Deficiência era considerada um problema de quem a possuía, assim, esta deveria tornar-se apta à integração ao meio social. Não cabia à escola se adaptar às necessidades dos alunos, mas às Pessoas com Deficiência adaptar-se à escola (inclusive em termos econômicos).

Destacamos aqui a ideia de integração física que envolvia a construção de classes especiais em escolas, mas organizadas de modo que também não atendiam plenamente à inclusão. Surge então a "inclusão total", que era a forma mais radical de legitimar a inclusão de todas as pessoas na classe regular e a proposta de eliminar os programas paralelos de educação especial.

$\mathrm{Na}$ década de 1990 reforçava-se cada vez mais a ideia de Educação Inclusiva para alunos com Deficiência. Com a proposta de aplicaçáo prática ao campo da educação a partir de um movimento mundial, denominado "Inclusão Social", surge o termo "Educação Inclusiva". Para Nascimento $(2014$, p. 18), "o movimento pela Educação Inclusiva significa uma crítica às práticas marginalizantes encontradas no passado, inclusive as da própria Educaçáo Especial".

Segundo Lima (2006), o ensino inclusivo não deve ser confundido com educação especial, embora o contemple. A educação especial nasceu a partir de uma proposta de educação para todos, independente da origem social de cada um. E a escola inclusiva, juntamente com uma sociedade inclusiva, refletiu-se em encontros internacionais, por meio de grupos que reivindicavam seus direitos sociais: 
O movimento mundial pela educação inclusiva é uma ação política, cultural, social e pedagógica, desencadeada em defesa do direito de todos os alunos de estarem juntos, aprendendo e participando, sem nenhum tipo de discriminação. A educação inclusiva constitui um paradigma educacional fundamentado na concepçâo de direitos humanos, que conjuga igualdade e diferença como valores indissociáveis, [...] dentro e fora da escola (BRASIL 2007, p. 1).

No Brasil, a Política Nacional de Educação Especial, na perspectiva da Educação Inclusiva, assegura acesso ao ensino regular a alunos com deficiências diversificadas: intelectual, física, surdos, cegos, com transtornos globais do desenvolvimento e a alunos com altas habilidades/superdotação, desde a educação infantil até a educação superior:

A sociedade inclusiva já começou a ser construída a partir de algumas experiências de inserção social de pessoas com deficiência, ainda na década de oitenta. Em várias partes do mundo, inclusive no Brasil, modificaçóes pequenas e grandes vêm sendo feitas em setores como escolas, empresas, áreas de lazer, edifícios e espaços urbanos, para possibilitar a participaçáo plena de pessoas deficientes, com igualdade de oportunidades junto à populaçáo geral (SASSAKI, 1998, p. 8).

A inclusão resulta da longa trajetória histórica que foi construída por todos ao longo dos anos, num processo marcado pela segregação, discriminaçáo e até morte. Segundo Blanco (2003, p. 72), quando se discute inclusão, não estamos "apenas repetindo um termo ou um conceito, mas referindo também aqueles que passaram suas vidas aprisionados em hospícios ou que acabaram em uma fogueira para salvar a alma de um corpo deficiente, como ocorreu na Idade Média”.

Acrescente-se ainda que o Brasil acompanhou os demais países e o ensino especial foi, na sua origem, um sistema separado de educação das crianças com deficiência, fora do ensino regular, baseado na crença de que as necessidades das crianças com deficiência não podiam ser supridas nas escolas regulares, pois, conforme Lima (2006), ainda não tínhamos recursos, não disponibilizávamos de professores capacitados, estruturas adequadas das escolas, dinâmica da escola para recebermos alunos especiais, recursos pedagógicos, entre outros.

Por meio dessa síntese histórica, pode-se notar como a situação da inclusão se apresenta de forma delicada, ao longo do tempo, a fim de compreendê-la nos dias atuais.

\section{Inclusão escolar}

A Educação Inclusiva é a transformação para uma sociedade inclusiva, um processo em que se amplia a participação de todos os alunos nos estabelecimentos de ensino regular. Trata-se de uma reestruturação da cultura, da prática e das políticas vivenciadas nas escolas, de modo que estas respondam à diversidade dos alunos. É uma abordagem humanística, democrática, que percebe o sujeito e suas singularidades, tendo como objetivos o crescimento, a satisfação pessoal e a inserção social de todos: 
A educação inclusiva pode ser definida como a prática da inclusão de todos - independentemente de seu talento, deficiência, origem socioeconômica ou cultural - em escolas e salas de aula provedoras, onde as necessidades desses alunos sejam satisfeitas (STAINBACK; STAINBACK, 1999, p. 21).

Martins et al. (2008, p. 19) acrescenta esse "movimento que busca repensar a escola, para que deixe de ser a escola da homogeneidade e passe a ser a escola da heterogeneidade, para que a escola da discriminação dê lugar à escola aberta a todos". Neste mesmo sentido, Mantoan (2003, p. 19) afirma que o mais relevante no conceito de inclusão escolar é que "todos os alunos, sem exceção, devem frequentar as salas de aula do ensino regular".

A escola é um ambiente multicultural, diversificado, que atende um público com objetivos, ideologias e necessidades diferenciadas. Enfim, essa é uma característica própria, que acolhe indivíduos com aspectos múltiplos, sejam religiosos, políticos, sociais, entre muitos outros. A escola é responsável pela transformação do indivíduo, o que corresponde a um conjunto de alterações comportamentais que se tem por aprendizagem.

Quando se trata de alunos com deficiência, é preciso compreender que o processo de aprendizagem é possível dentro de sala de aula regular e modificar o pensamento excludente de que esses alunos não são capazes de estudar, conviver e aprender com os demais. É na escola que este processo de transformação acontece de forma contínua (depois da família), é neste espaço único que os indivíduos são capazes de assimilar conteúdos, interagir e construir conhecimentos:

Ainda há profissionais que acreditam que a presença dos alunos com deficiência quebrará a rotina da escola. Por isso, temos que pensar em uma inclusão que afaste o pensamento de fracasso, assumindo posturas de novos ensinos e novas aprendizagens. Isso consiste em uma renovação da escola (CUNHA, 2015, p. 71).

Para Cunha (2015, p. 153), "em sala de aula, há inúmeras vozes que se cruzam, quando todos os alunos contribuem com seus pensamentos de forma a construir um diálogo, através do qual se pode colher assim os frutos do conteúdo abordado”.

A escola possui função essencial na vida dos alunos, ela tem um importante papel que proporciona desenvolvimento cultural, social, intelectual e físico dos escolares. À ela é atribuída inúmeras funções na vida do indivíduo, como responsável pela educação formal, na promoção de valores sociais e culturais indispensáveis à formação do cidadão:

A escola não pode continuar ignorando o que acontece ao seu redor. Não pode continuar anulando e marginalizando as diferenças - culturais, sociais, étnicas - nos processos pelos quais forma e instrui os alunos. Afinal de contas, aprender implica ser capaz de expressar, dos mais variados modos, o que sabemos; implica representar o mundo a partir de nossas origens, de nossos valores e sentimentos (MANTOAN, 2003, p. 15). 
É preciso que a escola ande em conformidade com a família, numa proposta de educação compartilhada, principalmente no caso dos alunos com deficiência, para que haja resultado satisfatório de aprendizagem dos alunos.

Um ponto importante que precisa ser destacado para incluir alunos com deficiência está na qualificaçáo da equipe de profissionais escolares e dos recursos pedagógicos. Não podemos falar somente em inclusão escolar de forma passional, mas devemos fazer o debate segundo a visão de quem faz a escola, sejam professores, coordenadores, diretorias, porteiros, entre outros. Não basta que o aluno seja matriculado por força da lei em uma turma de ensino regular, pois é de fundamental importância uma equipe preparada para que a inclusão se efetive. Conforme Cunha (2015, p. 69), "incluir é muito mais que inserir. Além de tudo, é preciso dar condiçôes de permanência e possibilidade de desenvolvimento da aprendizagem, maximizando, assim, suas potencialidades", ou seja,

É necessário que essa discussão se estenda para que não só os intelectuais e especialistas saibam que os indivíduos com necessidades educacionais especiais têm potencialidades, inteligência, sentimentos, direito à dignidade, mas também que eles têm direito à vida, em todos os seus aspectos, apesar das limitaçóes que possam ter. Todos nós temos limitaçóes; é preciso apenas respeitá-las (SOUZA, 2013, p. 162).

De acordo com Cunha (2015), a inclusão de Pessoas com Deficiência na escola precisa de fundamentos teóricos, como também da lida diária da prática para estabelecer dados concretos que incentivem, guiem e deem segurança aos educadores. Também é preciso que o sistema de Educação Inclusiva observe as necessidades gerais dos alunos, exigindo da escola sensibilidade em trabalhar com as individualidades.

A Educação Inclusiva tem por proposta a educaçáo de todos os alunos juntos, deixando-os aptos para o convívio em sociedade a partir da escola, conforme afirma Mantoan (2003, p. 33), "incluir é não deixar ninguém de fora da escola comum, ou seja, ensinar a todas as crianças indistintamente".

Quando os alunos com diversos níveis de deficiências estão numa sala inclusiva, eles podem aprender mais e melhor, assim como aos demais é dada a oportunidade de aprendizado, compreensão, respeito e convivência com as diferenças.

Conforme falamos anteriormente, a escola atual tem uma demanda bastante diversificada de estudantes, entretanto, a inserção de alunos com deficiência no ensino regular, ainda é considerada um desafio. Infelizmente, ainda vemos muitas escolas com uma prática excludente, cometendo os mesmos equívocos de segregação de séculos passados:

Quando as pessoas com deficiência eram excluídas da sociedade sob a alegação de que eram incapazes ou incapacitadas, e por isso eram postas à margem do convívio social, inclusive da acessibilidade à escola. Esse processo passa por mudanças atitudinais e, principalmente, pela existência de leis que assegurem direitos às pessoas com deficiência (CUNHA, 2015, p. 70-71). 
Porém, hoje o discurso é que os professores não estão preparados para receber o aluno com deficiência e a escola não dispôe de infraestrutura adequada e não possui recursos didático-pedagógicos para atender esse público, mesmo sendo um direito estabelecido por lei.

É preciso entender que a inclusão de Pessoas com Deficiência no ensino regular é fazê-las integrantes da escola num sistema único de educação. Nas escolas de educação especial, os alunos conviviam somente com outros com deficiências (iguais ou diferentes da dele). Todavia, vivemos em um momento em que o mundo prega o respeito à diversidade, e que esta seja entendida como um processo natural, pois "defender a inclusão escolar é necessário para que seja dada a oportunidade a todos os alunos de estarem na escola e, juntos, aprenderem o respeito às diferenças" (CUNHA, 2015, p. 71).

A escola inclusiva apresenta a característica de ajudar os alunos que sozinhos não conseguem solucionar problemas devido a sua deficiência, e superar seus limites. Faz-se necessário esforço contínuo, com a finalidade de colaborar com o outro, logo,

Se não houver outra utilidade, adaptar as escolas e as turmas para incluir todos significa dizer, implicitamente, "a escola pertence a todos". Qualquer cultura que diga "você é importante" aumenta a probabilidade de seus membros serem capazes de dizer o mesmo uns para os outros e para si mesmos (STAINBACK; STAINBACK, 1999, p. 404).

A inclusão escolar perpassa pelas várias dimensóes humanas, sociais e políticas, e vem gradualmente se expandindo na sociedade contemporânea, de forma a auxiliar no desenvolvimento das pessoas em geral, de maneira a contribuir para a reestruturação de práticas e açôes cada vez mais inclusivas e sem preconceitos.

O conceito de Inclusão no âmbito específico da Educação implica, antes de mais, rejeitar por princípio a exclusão (presencial ou acadêmica) de qualquer aluno da comunidade escolar. Para isso, a escola que pretende seguir uma política de Educação Inclusiva (EI), desenvolver políticas, culturas e práticas que valorizam o contributo activo de cada aluno para a construçáo de um conhecimento construído e partilhado e, dessa forma, atingir a qualidade académica e sociocultural sem discriminação. (RODRIGUES, 2006, p. 2).

Para Mantoan (2003, p. 28), "as crianças precisam da escola para aprender e não para marcar passo ou ser segregada em classes especiais e atendimentos à parte". A Educação Inclusiva se configura na diversidade inerente à espécie humana, buscando perceber e atender as necessidades educativas especiais de todos os sujeitos-alunos, em salas de aulas comuns, em um sistema regular de ensino, de forma a promover a aprendizagem e o desenvolvimento pessoal de todos. Prática pedagógica coletiva, multifacetada, dinâmica e flexível requer mudanças significativas na estrutura e no funcionamento das escolas, na formação humana dos professores e nas relaçóes família-escola: 
Educação Inclusiva não consiste apenas em matricular o aluno com deficiência em escola ou turma regular como um espaço de convivência para desenvolver sua 'socialização'. A inclusão escolar só é significativa se proporcionar o ingresso e permanência do aluno na escola com aproveitamento acadêmico, e isso só ocorrerá a partir da atençáo às suas peculiaridades de aprendizagem e desenvolvimento. (GLAT; PLETSCH; FONTES, 2007, p. 344).

Para Carvalho (2007), a Educação Inclusiva pode ser definida como a prática da inclusão de todos, independente de seu talento, deficiência, origem socioeconômica ou cultural. A proposta de Educação Inclusiva traduz uma aspiração antiga, se devidamente compreendida como educação de boa qualidade para todos e com todos, buscando meios e modos de remover barreiras para aprendizagem e para a participação dos aprendizes, indistintamente. De acordo com Cunha (2015, p. 63), a aprendizagem não deve ser confundida com os processos naturais de crescimento humano, pois ela envolve um indivíduo nas mais diferentes etapas da vida, isto é, quando se aprende algo náo se esquece:

Educação Inclusiva significa pensar uma escola em que é possível o acesso e a permanência de todos os alunos, e onde os mecanismos de seleção e discriminação, até então utilizados, são substituídos por procedimentos de identificação e remoção das barreiras para a aprendizagem (BLANCO, 2003, p. 16).

A inclusão vem demonstrar que as pessoas são igualmente importantes em determinada comunidade, e, com isso, a diversidade e as diferenças tornam o meio escolar culturalmente rico, possibilitando novas aprendizagens para Pessoas com Deficiência ou pessoas que por qualquer motivo não se adaptam ao sistema escolar e são excluídas. De acordo com Lima (2006), tal inclusão é o modo ideal de garantir igualdade de oportunidades e permitir que alunos com deficiência possam relacionarse com outros e estabelecer trocas para construir uma sociedade mais igualitária e consciente da necessidade de inclusão. Nessa relação, todos se desenvolvem, pois são necessários exemplos que superem fraquezas e despertem potencialidades; a igualdade nos relacionamentos permite trocas e não estagna o desenvolvimento. Dentro de um amplo projeto de educação, os princípios da inclusão vão além de inserir crianças com deficiência na rede regular de ensino.

É preciso que entendamos que o ato de incluir é, antes de tudo, uma lição de cidadania e de respeito para com o próximo. Incluir é reconhecer que existem outros de nós que precisam participar de todos os meios, seja profissional, educacional, social, independente das diferenças.

A inclusão escolar não é um trabalho fácil. Estamos a rediscutir valores e preconceitos que estão enraizados em nossa cultura, mas estamos no caminho para alcançar a inclusão plena, pois é necessária uma reestruturação progressiva e uma transformação do pensar a escola. 


\section{Considerações finais}

Para uma sociedade efetivamente democrática, na qual todos tenham uma vida decente, é preciso fazer da inclusão escolar uma realidade. A democracia não pressupóe atender a maioria da sociedade, mas garantir o direito de todos. Uma sociedade só é democrática quando cada um de nós também for democrático:

A sociedade inclusiva é, sim, possível, e, sem dúvida, será uma sociedade melhor não apenas para as pessoas com deficiências, com deficiências significativas, precariamente ou marginalmente incluídas, mas será uma sociedade muito melhor, muito mais digna, para todos nós (NASCIMENTO, 2014, p. 45).

É grande a possibilidade da inclusão. Sabemos que ainda há um longo percurso pela frente para que a inclusáo escolar seja plena e não precisamos ir muito longe, basta olhar ao nosso redor, que logo veremos um grande caminho para construirmos uma sociedade inclusiva.

Ambientes inclusivos propiciam integração social, o que afeta diretamente, através dos colegas, o desenvolvimento de potencialidades. Torna-se evidente o contexto mais produtivo, pois há promoção de habilidade de interação social, quando se compara com ambientes educacionais segregados. É a capacidade de indignação frente às injustiças, de não aceitar que os nossos pares sejam tratados como indesejáveis, o que nos mantém determinados e empenhados na soluçáo da causa. A luta pela inclusáo acontece no dia a dia, enxergando o nosso próximo com respeito, independentemente do tipo e nível de deficiência.

Quando de fato acontecer a inclusão de todos os indivíduos, podemos dizer que avançamos muito na mudança de mentalidade da sociedade. Não é uma tarefa simples, mas é possível. Devemos defender a causa e seguiremos em frente para que tal cidadania realmente aconteça.

\section{Referências}

AMARAL, L. A. Pensar a Diferença/Deficiência. Brasília: Coordenadoria Nacional para Integração da Pessoa Portadora de Deficiência. 2001.

BLANCO, R. Aprendendo na diversidade: Implicaçōes educativas. Foz do Iguaçu: 2003. Disponível em: $<$ http://entreamigos.org.br/sites/defaut/files/textos/Aprendendo\%20na\%20Diversdade20\%20Implica \%C3\%A7\%C3\%B5es\%20Educativas.pdf>. Acesso em 08 de mar de 2016.

BRASIL. Lei $\mathbf{n}^{\circ}$ 9394, de 20 de dezembro de 1996. Lei de diretrizes e bases da educação nacional. [da] $185^{\circ}$ da Independência e $108^{\circ}$ da República, Brasília, 1996. Disponível em: < http://www.planalto.gov.br/ccivil_03/ Leis/L9394.htm>. Acesso em 10 de jun de 2015.

BRASIL, Secretaria de Educação Fundamental. Parâmetros curriculares nacionais: Educação Física. Brasília: MEC/SEF, 1998.

BRASIL, Ministério da Educação. Atendimento Educacional Especializado: Deficiência Visual. Brasília: SEESP/SEED/MEC, 2007.

BRASIL, Ministério da Educação. Política Nacional de Educação Especial na Perspectiva da Educaçáo Inclusiva. Brasília: SEESP/MEC, 2007.

CARVALHO, R. E. Educaçáo Inclusiva: com os pingos nos “is". 5. ed. Porto Alegre: Mediação, 2007.

CUNHA, M. S. Ensino da língua portuguesa na perspectiva da inclusão do aluno cego no nível fundamental. 2015. 173 f. Dissertação (Mestrado em Educação) Programa de Pós Graduação em Educação. Universidade Federal de Sergipe. 2015. 
GLAT, R.; PLETSCH, M. D.; FONTES, R. de S. Educação inclusiva \& educação especial: propostas que se complementam no contexto da escola aberta à diversidade. In: Revista em Educaçáo. Santa Maria, v. 32, n. 2, p. 343-356. 2007. Disponível em: <http://coralx.ufsm.br/revce/2007/a5.htm>. Acesso em 08 de mar de 2016.

LIMA, P. A. Educaçáo Inclusiva e Igualdade Social. São Paulo: Avercamp, 2006.

MANTOAN, M. T. E. Inclusão escolar: o que é? por quê? como fazer? São Paulo: Moderna, 2003.

MARTINS, L. A. R.; et al. Inclusão: compartilhando saberes. 3. ed. Petrópolis/RJ: Vozes, 2008.

NASCIMENTO. L. B. P. A importância da inclusáo escolar desde a educaçáo infantil. 2014. 49 f. Trabalho de Conclusão de Curso (Pedagogia). Departamento de Educação - Faculdade Formaçăo de Professores. Universidade do Estado do Rio de Janeiro. 2014.

RODRIGUES, D. Inclusão e Educação: doze olhares sobre a educação inclusiva. São Paulo: Summus, 2006.

SASSAKI, R. K. Entrevista. In: Revista Integraçáo, Brasília, v 8, n. 20, p. 8-10, ago. 1998.

SILVA, R. F.; SEABRA JÚNIOR L.; ARAÚJO, P. F. Educaçáa Física Adaptada no Brasil: da história à inclusão educacional. São Paulo: Phorte, 2008.

SOUZA, J. P. de. A Educaçáo Física no contexto inclusivo: análise do curso de capacitação de professores multiplicadores em Educação Física Adaptada. Campo Grande, 2006. 133 f. Dissertação (Mestrado em Educação), Programa de Pós Graduação em Educação. Universidade Católica Dom Bosco 2006.

SOUZA, R. C. S.; et al. Educaçáo Física Inclusiva: perspectiva para além da deficiência. Aracaju: Editora UFS, 2013.

SOUZA, R. C. S.; BORDAS, M. A. G.; SANTOS, C. S. Formaçáo de Professores e Cultura Inclusiva. Aracaju: Editora UFS, 2014.

STAINBACK S.; STAINBACK W. Inclusão: Um guia para Educadores. Porto Alegre: Artmed, 1999.

\section{Correspondência}

Antenor de Oliveira Silva Neto - Faculdade de Ciências Humanas e Sociais de Paripiranga. Avenida Universitária, 23. Parque das Palmeiras. CEP: 48430-000. Paripiranga, Bahia, Brasil.

E-mail: antenoneto@hotmail.com - everton.vila12@gmail.com - tamara.sales89@hotmail.com - simone.silveira@unit.br - andrea_karla@unit.br - vera_santos@unit.br

Recebido em 21 de setembro de 2016

Aprovado em 08 de maio de 2017 